\title{
Role of Radiological Investigations of COVID-19 Patients with Pneumonia, Karachi Pakistan
}

\author{
Samia Perwaiz Khan1, Safia Izhar², Shazia Kadri² \\ ${ }^{1}$ HOD Department of Pharmacology, Jinnah Medical \& Dental College, Sohail University, Karachi, Pakistan \\ ${ }^{2}$ Department of Radiology, Medicare Cardiac \& General Hospital, Jinnah Medical \& Dental College, Karachi, Pakistan \\ Email: samiaphk@gmail.com, safiaizhar123@yahoo.com,shazia_wk@hotmail.com
}

How to cite this paper: Khan, S.P., Izhar, S. and Kadri, S. (2021) Role of Radiological Investigations of COVID-19 Patients with Pneumonia, Karachi Pakistan. Open Journal of Radiology, 11, 35-44.

https://doi.org/10.4236/ojrad.2021.111004

Received: January 26, 2021

Accepted: March 6, 2021

Published: March 9, 2021

Copyright () 2021 by author(s) and Scientific Research Publishing Inc. This work is licensed under the Creative Commons Attribution International License (CC BY 4.0).

http://creativecommons.org/licenses/by/4.0/ (c) (i) Open Access

\begin{abstract}
The study was conducted to determine the role of radiological investigation in assessing the severity of COVID-19 pneumonia with the help of chest X-ray (CXR), high resolution computed tomography (HRCT), and ultrasound. This was a retrospective study conducted on 105 COVID-19 patients with symptoms of fever, cough, dyspnea, loss of sense of smell and taste, body ache. Diagnostic tests PCR were positive for COVID-19 included from Medicare Cardiac and General Hospital and Jinnah Medical College Hospital Korangi (JMCH) from April to November 2020. Written informed consent was taken from all participants. This study was approved by ethical review committee, Jinnah Medical \& Dental College. Real time-PCR (RT-PCR) was done for the confirmation. Radiological imaging including Chest X-ray, HRCT chest, and ultrasound was done to study the severity of symptoms. Sixty-five patients had mild to moderate symptoms with oxygen saturation between $96 \%-98 \%$ and 30 patients with severe pneumonia had between saturation $50 \%-55 \%$. Patients with mild symptoms were followed up by chest X-ray showing mostly normal chest X-rays but single or patches of ground glass opacities (HRCT). HRCT of 10 patients with low oxygen saturation 50\% were already done showing bilateral peripheral patchy consolidation predominantly involving mid and lower lobes. 3 patients presented with patchy lung opacities and ultrasound showing similar findings with pleural effusion and ascites. Radiological imaging, specially CT-Scan was highly significant for diagnosing COVID-19 and severity of infection even in patients with negative PCR. Chest $\mathrm{X}$-ray and ultrasound were also found to be a very useful tool.
\end{abstract}

\section{Keywords}

High Resolution Computed Tomography Scan (HRCT-Scan), CXR-Chest 
X-Ray, Ultrasound, Ground Glass Opacities, Corona Virus Disease 2019, COVID-19

\section{Introduction}

Corona Virus disease 2019 (COVID-19) is a highly contagious, infectious disease caused by severe acute respiratory syndrome coronavirus 2 (SARS-CoV-2). The viral infection is spreading fast and initial more deaths were seen in elderly people [1]. Some cases were reported from Wuhan, China, in December 2019 before it spread globally and was declared as pandemic by World Health Organization (WHO) on 11th March 2020 [1]-[6]. The first scientific article about corona virus stated the outbreak of viral infection in Wuhan China. These patients developed severe pneumonia and diagnosis was done by laboratory testing and radiological imaging. Pathology is caused by droplet infections. There are efforts required on local and global levels to control the dissemination of disease and confine the spread as effectively as possible [7]. This virus is very dangerous and enters the host cell by particular enzyme named angiotensin converting enzyme 2 receptors which are present in lungs and later may spread to other organs of body results in multi-organ failure [8]. Early diagnosis and management reduced mortality rate. Isolation and quarantine of the residents were the immediate measures taken. Radiological finding shown to be an important tool in diagnosis, severity and outcome of treatment in patient infected by COVID-19 since this viral infection develops into a global pandemic now and is the most serious health problem affecting the world health in 2020. Diagnosis and severity of the diseases are most essential not only to prevent the spread of the diseases but also to reduce morbidity and mortality. Clinical presentation of this infection includes high grade fever, cough, body ache, shortness of breath and generalized fatigue [5] [6]. Isolation of the patients diagnosed as COVID-19 positive is the initial and foremost measure. For prevention, wearing masks, frequent hand washing, social distancing and self-isolation (infected patients) were suggested as the most effective measure to avoid spread to infection [7] [8] [9]. Study done in February 2020 has shown that HRCT (High resolution computed tomography) is the most effective imaging technique used to diagnose the pneumonia and the lung parenchymal changes with severe pneumonia in COVID-19 patients. HRCT was found to be more sensitive as compared to RT-PCR by taking a nasal or pharyngeal swab which was found to give false negative even in presence of symptoms [10]. The HRCT features in COVID-19 patients after the onset of symptoms of dyspnea and reduced oxygen saturation were multi-lobar involvement bilaterally and frequently in the mid and lower lobes of lungs. Diffused bilateral rounded ground glass opacities peripherally were early findings which progressed to consolidation in more seriously ill patients [11] [12]. Shi, et al. [11] has reported ground glass opacities in 15 COVID-19 positive health profession- 
als without symptoms of this diseases. Portable Chest X-ray found to be useful not only to prevent infection but to avoid shifting of patients and reduce the use of personal protective equipment by health care workers which ran short due to rapid increase in number of hospitalized patients. Although Chest X-ray (CXR) is not useful in diagnosis in early disease, it can be useful in the follow-up or the progress of these patients [11] [12]. Another study done on asymptomatic COVID-19 positive patients, who were passengers on Diamond cruise ship 54\% had positive CT-Scan findings [13]. Hafeez, et al. [14] studied that Chest X-ray and HRCT to as to be highly sensitivity for detection pneumonia in COVID-19 patients. Radiographic abnormalities, when present, may similar to those of HRCT with bilateral lower zone- and peripherally-predominant consolidation and hazy opacities. Ultrasound is convenient and low-cost tool for diagnosis and assessment of lung parenchyma changes without exposure to radiations. This is especially useful in clinical settings with limited resources. Peng et al. [15] study on lung sonographic findings in patients with COVID-19 has shown similarity to typical CT abnormalities. RT-PCR is the basis of diagnostic testing for COVIDpositive cases. But since a number of cases have shown to reported false negative even though positive. This is serious issue in those patients who are having symptoms of this highly contagious infectious diseases such as high grade fever, loss of sense of taste and smell, headache or body ache and shortness of breath but have been reported COVID-19-negative on RT-PCR or serological testing. The radiological investigation including Chest X-ray, HRCT and ultrasound are essential for the determining the severity of the diseases. Aim of this study is to determine the imaging features as most useful tool for diagnosis and assessment of severity due to this highly contagious viral disease.

\section{Material \& Methods}

Patients: 105 COVID-19 infected patients with clinical symptoms of high grade fever, cough, shortness of breath, reduced oxygen saturation or diagnosed with COVID-19 test were included in the study. This study was approved by ethical review committee; Jinnah Medical \& Dental College. Written informed consent taken from all participants. Duration of the study was of three months, from April to November 2020.

Inclusion Criteria: All those patients with symptoms of COVID-19 and shortness of breath, positive RT-PCR and reduced oxygen saturation were included in the study.

Exclusion Criteria: Chest infection other than COVID, and patients with difficulty in breathing with normal oxygen saturation.

Ethical Review Committee Approval: Protocol \# 00039/20.

Clinical features recorded for patient tested COVID-19 suspected cases. Real Time- PCR was the test done to evaluate patient if were COVID positive or negative. Severity of condition, laboratory findings, and radiological findings were recorded. Chest X-ray was performed for all patients with symptoms of pneu- 
monia. High resolution computed tomography was done in COVID-19 infected patients to determine severity of infection (ground glass opacities, lung consolidation and fibrosis). Ultrasound imaging was done in patients with symptoms of pneumonia, pleural effusion and ascites.

\section{Results \& Analysis}

Total 105 COVID-19 infected patients were in age range between 18 - 60 years. There were 60 males and 35 females. Sixty five patients had mild to moderate symptoms with oxygen saturation between $95 \%-98 \%$ and 30 had between $50 \%$ $60 \%$ with complains of high grade fever, cough and shortness of breath. All patients were followed up later on Chest X-rays. Patients with mild symptoms were also followed up by chest X-ray showing mostly normal chest X-rays but only single or patches of ground glass opacity may seen on high resolution computed tomography. Five patients have low oxygen saturation. There was a 25 year old female patient with symptoms of COVID-19, her PCR test was negative but HRCT chest showed typical bilateral peripheral ground glass opacities. As her condition deteriorated so her RT-PCR was repeated 4th time which turned out positive. There were severe cases with co-morbids (diabetes mellitus, hypertension, cardiovascular diseases, pregnancy, immunocompromised and a patient who was already diagnosed case of Myasthenia gravis along with diabetes mellitus and hypertension, developed severe symptoms on HRCT shown patchy ground glass opacities and pleural effusion. The imaging findings of pleural effusion and ascites seen in 3 patients as ultrasound were done due to complain of abdominal pain and diarrhea.

The data was collected using SPSS 20.0. The results were statistically analyzed and student's-test. Student's t-test was applied to compare quantitative variables, p-value 0.05 was considered significant. Categorical variables were given as percentages.

Table 1 shows characteristics of patients with clinical symptoms of COVID-19 infected patients with pneumonia.

Table 2 shows investigation tests done for confirmation of COVID-19 diagnosis. Real time-PCR and C-RP C-Reactive protein.

Table 3 shows radiological findings in COVID-19 infected patients. High resolution computed tomography, Chest X-ray and ultrasound imaging.

Figure 1 shows high resolution computed tomography scans showing bilateral peripheral patchy consolidation and fibrosis predominantly involving mid and lower lobes.

Figure 2 shows chest X-ray: 33 years old complained of cough and difficulty in breathing shows patchy opacities in mid and lower zone of both lungs predominantly peripherally.

Figure 3 shows ultrasound image showing left side Pleural effusion.

Figure 4 shows ultrasound Chest \& Abdomen in COVID-19 patient with Pleural effusion \& Ascites. 
Table 1. Characteristics and clinical symptoms of COVID-19 patients with pneumonia.

\begin{tabular}{ccc}
\hline $\mathbf{N}=105$ & $\begin{array}{c}\text { Severe } \\
(\mathbf{n}=\mathbf{3 0})\end{array}$ & $\begin{array}{c}\text { Mild/moderate } \\
(\mathbf{n}=\mathbf{6 5})\end{array}$ \\
\hline Age & $30-60$ years & $18-30$ years \\
Gender & & \\
$\mathrm{M}$ & 20 & 40 \\
$\mathrm{~F}$ & 10 & 25 \\
Fever & 30 & 75 \\
Cough & 30 & 60 \\
Dyspnea/shortness of breath & 30 & 75 \\
O2 saturation & $50 \%-60 \%$ & $92 \%-98 \%$ \\
Fatigue & 30 & 75 \\
Bodyache & 30 & 75 \\
Loss of smell \& taste & 20 & 60 \\
Co-morbids & & 60 \\
- Diabetes & 30 & 5 \\
- Hypertension & 10 & 10 \\
- Pardiovascular Diseases & 5 & \\
- Immuncy & 2 & \\
- Ryasthenia Gravis & 3 & \\
\hline
\end{tabular}

Table 2. Investigations done for confirmation COVID-19 infection in patients with pneumonia.

\begin{tabular}{cccc}
\hline $\begin{array}{c}\text { Investigation } \\
\mathbf{N}=105\end{array}$ & $\begin{array}{c}\text { COVID-19 } \\
\text { patients }\end{array}$ & $\begin{array}{c}\text { COVID-19 } \\
\text { patients }\end{array}$ & P-value \\
\hline Real Time-PCR & 90 (positive) & 25 (negative) & 0.05 \\
C-Reactive Protein & 70 (raised) & 35 (normal) & 0.05 \\
\hline
\end{tabular}

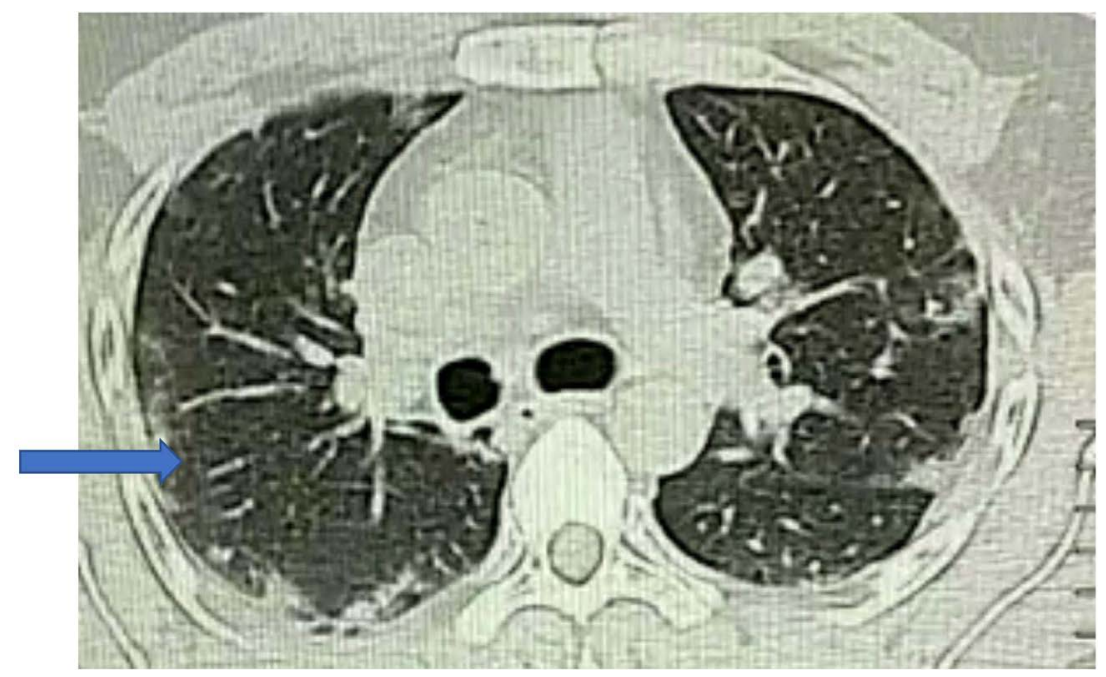

Figure 1. HRCT Chest: Bilateral patches of ground glass opacity in both lungs. 
Table 3. Radiological findings of COVID-19 patients with pneumonia.

\begin{tabular}{|c|c|c|c|}
\hline $\begin{array}{c}\text { Radiological } \\
\text { Investigations }(\mathrm{N}=105)\end{array}$ & $\begin{array}{l}\text { Radiological } \\
\text { Findings }\end{array}$ & $\begin{array}{l}\text { No. of Patients } \\
\quad(N=105)\end{array}$ & $\begin{array}{l}\text { Percentage } \\
\text { (\%) }\end{array}$ \\
\hline HRCT-SCANS & $\begin{array}{l}\text { - Bilateral ground glass opacities and } \\
\text { consolidation }\end{array}$ & 85 & $85 \%$ \\
\hline \multirow{2}{*}{ CHEST-X-RAYS } & - Bilateral, peripheral, patchy opacities. & 100 & $90 \%$ \\
\hline & - Fibrosis & 5 & $5 \%$ \\
\hline ULTRASOUND CHEST & - Pleural effusion, Ascites. & 5 & $5 \%$ \\
\hline
\end{tabular}

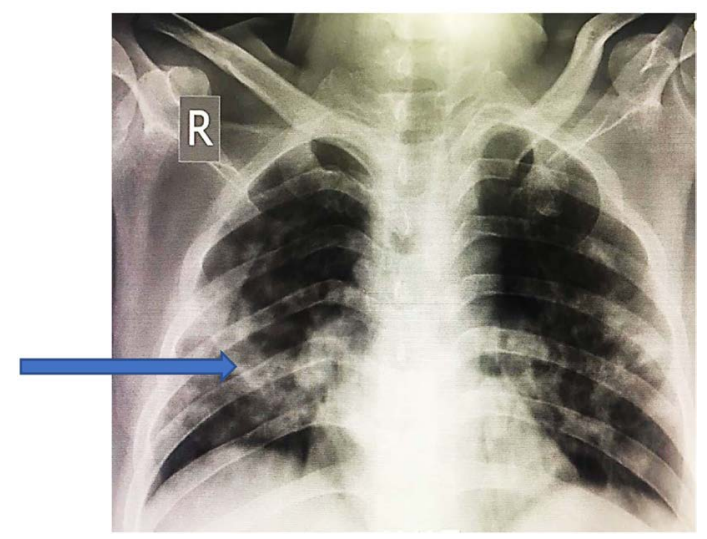

Figure 2. Chest X-ray: 33 year old complained of cough and difficulty in breathing shows patchy opacities in mid and lower zone of both lungs predominantly peripherally.

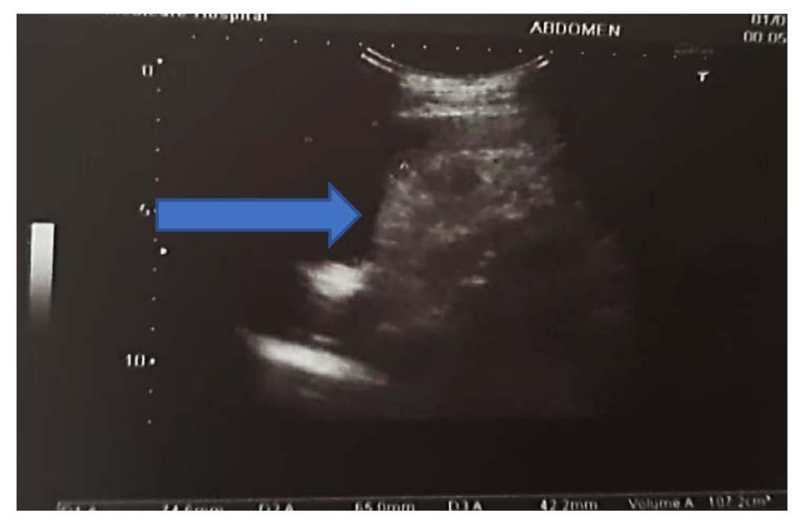

Figure 3. Ultrasound image showing left side pleural effusion.

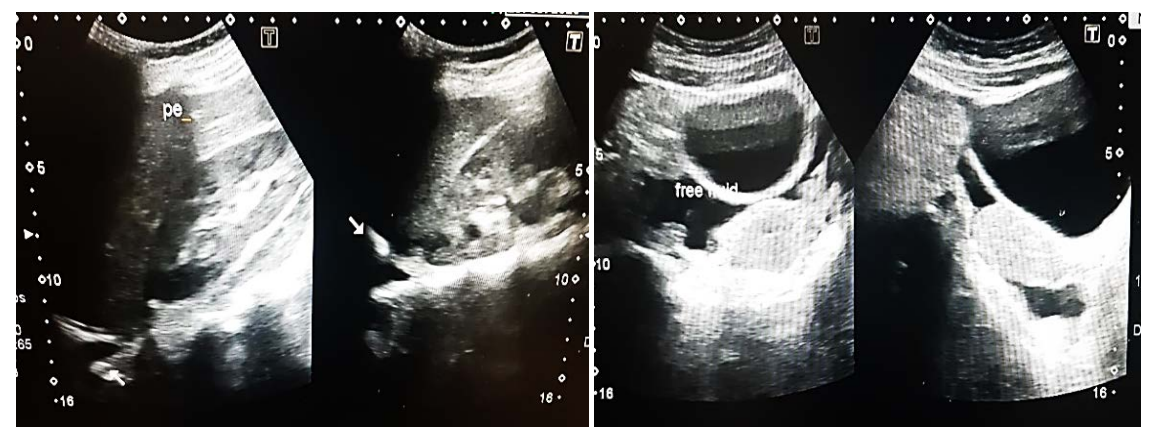

Figure 4. Ultrasound chest \& abdomen in COVID-19 patient with pleural effusion \& ascites. 


\section{Discussion}

International outbreak of COVID-19 infection spread to the whole world [4]. Pandemic when occurs needs extra ordinary effort to be dealt with in terms of its rapid spread in different age groups and gender. There is vaccine or other preventive and curative treatments required to deal with it. The virus spreads from one human to another by droplets, aerosols, and fomites. The first case of COVID-19 was reported in February 2020 in Pakistan. Immediate RT-PCR [5] testing started as the basic test for diagnosing COVID-19 infection in order to make early diagnosis and limit the spread of infection by quarantine patients in time and also for early treatment preventing major morbidity and mortality. These patients had symptoms of fever, sore throat, body aches, shortness of breath and loss of taste and smell [6].

Initial constrains of PCR test due to inadequate nasopharyngeal sampling, limited testing kits and uncomfortable procedures. To see the severity of disease radiological imaging played vital role in these patients. Chest X-ray and high resolution computed tomography are used to decide the appropriate management according to severity of disease. As our study has shown that bilateral peripheral patchy opacities predominantly in mid and lower lung zones seen on Chest X-rays and in more details on computed tomography scans. Extensive consolidation is seen in severely ill patients. These findings were mostly noticed on 10 - 12 day of onset of disease as reported by Wong et al. [12] Despite the less sensitivity, studies show that chest X-ray [13] [14] is an ideal and cheap radiological base line investigation in COVID-19 patients however HRCT chest can pick up subtle early ground glass haze which can be missed on X-rays. Our study also supports this. Study was using ultrasound as a diagnostic tool showing characteristic changes labelled as B lines due to edema and A lines on follow up images when air way improved [15] ultrasound scan found pleural effusion and ascites in 3 severely ill patients. Another study done by Wang et al. [16] showing ground glass opacities on initial imaging which later converted to extensive consolidation as the severity of disease increased. Similar features are seen in our study also. Follow up imaging usually done to see the fibrosis and extent of disease in COVID-19 patients [17]. A case report also published emphasizing the importance of HRCT in progression of disease in order to decide the appropriate management [18]. Although no appropriate treatment has been established for COVID-19, some centers found Remdesivir [19] [24] as beneficial antiviral therapy initially. Dexamethasone also found was useful for recovery in severe ill patients. As mentioned before the limitation of testing RT-PCR kits and sensitivity of test, HRCT showed promising results. [20]. This is the requirement of time that Radiologist should be well trained in radiological appearances of COVID-19 [21] [22]. Antiviral therapy, social distancing and boosting immune system, may control and prevent the spread of infection [23] [24].

\section{Conclusion}

Radiological investigation has a vital role in detecting COVID-19 infection and 
its severity. HRCT and chest X-ray can be considered as a primary screening tool due to characteristic radiological appearances of this infection. These modalities proved as essential tools in diagnosis and determination of the severity of COVID-19 infection.

\section{Limitations of Study}

Sample size is small as the hospital admission of COVID-19 infected patients is restricted due to reduced availability of hospital beds.

\section{Acknowledgements}

Medicare Cardiac \& General Hospital and JMCH and patients.

\section{Grant Support and Financial Disclosures}

None.

\section{Authors Contributions}

SPK: Methodology and article writing, data collection, reviewing.

SI: Patient information and data collection Responsibility of accuracy and integrity of work.

SK: Concept and reviewing, review of Imaging.

\section{Conflicts of Interest}

The authors declare no conflict of interest.

\section{References}

[1] Wang, W., Tang, J. and Wei, F. (2020) Updated Understanding of the Outbreak of 2019 Novel Coronavirus (2019-nCoV) in Wuhan, China. Journal of Medical Virology, 92, 441-447. https://doi.org/10.1002/jmv.25689

[2] Parry, J. (2020) Pneumonia in China: Lack of Information Raises Concerns among Hong Kong Health Workers. BMJ, 368, m56. https://doi.org/10.1136/bmj.m56

[3] WHO (2020) Novel Coronavirus-China. https://www.who.int/csr/don/12-january-2020-novel-coronavirus-china/en

[4] Huang, C., Wang, Y., Li, X., Ren, L., Zhao, J., Hu, Y., et al. (2020) Clinical Features of Patients Infected with 2019 Novel Coronavirus in Wuhan, China. The Lancet, 395, 497-605. https://doi.org/10.1016/S0140-6736(20)30183-5

[5] Shuren, J. and Timothey, S. (2020) COVID-19 Molecular Diagnostic Testing-Lessons Learned. The New England Journal of Medicine, 383, e97. https://doi.org/10.1056/NEJMp2023830

[6] Wu, Z. and McGoogan, J.M. (2020) Characteristics of and Important Lessons from the Coronavirus Disease 2019 (COVID-19) Outbreak in China: Summary of a Report of 72314 Cases from the Chinese Center for Disease Control and Prevention. JAMA, 323, 1239-1242. https://doi.org/10.1001/jama.2020.2648

[7] Guan, W.J., Ni, Z.Y., Liang, W.H., Ou, C.Q., He, J., Liu, L., et al. (2020) Clinical Characteristics of Coronavirus Disease 2019 in China. The New England Journal of Medicine, 382, 1708-1720. https://doi.org/10.1056/NEJMoa2002032 
[8] Ni, W., Yang, X., Yang, D., Bao, J., Li, R., Xiao, Y., et al. (2020) Role of Angiotensin-Converting Enzyme 2 (ACE 2) in COVID-19. Critical Care, 24, 422. https://doi.org/10.1186/s13054-020-03120-0

[9] UK Government (2020) COVID-19: Guidance for Households with Possible Coronavirus Infection.

https://www.gov.uk/government/publications/covid-19-stay-at-home-guidance/stay -at-home-guidance-for-households-with-possible-coronavirus-covid-19-infection

[10] US Centers for Disease Control and Prevention (2020) Coronavirus (Covid-19). CDC. https://www.cdc.gov/coronavirus/2019-ncov/index.html

[11] Shi, H., Han, X., Jiang, N., Cao, Y., Alwalid, O., Jin, G., Fan, Y. and Zheng, C. (2020) Radiological Findings from 81 Patients with COVID-19 Pneumonia in Wuhan, China: A Descriptive Study. The Lancet Infectious Diseases, 20, 425-434.

https://doi.org/10.1016/S1473-3099(20)30086-4

[12] Wong, H.Y.F., Lam, H.Y.S., Fong, A.H.-T., Leung, S.T., Chin, W.Y., Lo, C.S.Y., et al. (2019) Frequency and Distribution of Chest Radiographic Findings in Patients Positive for COVID-19. Radiology, 2019, Article ID: 201160.

https://doi.org/10.1148/radiol.2020201160

[13] Inui, S., Fujikawa, A., Jitsu, M., Kunishima, N., Watanabe, S., Suzuki, Y., et al. (2020) Chest CT Findings in Cases from the Cruise Ship "Diamond Princess" with Coronavirus Disease 2019 (COVID-19). Radiology: Cardiothoracic Imaging, 2, e200110. https://doi.org/10.1148/ryct.2020200110

[14] Hafeez, M. and Sattar, M. (2020) Contributions and Challenges of Radiology in the Era of COVID-19 Pandemic. Journal of the College of Physicians and Surgeons Pakistan, 30, s84-s85. https://doi.org/10.29271/jcpsp.2020.Supp1.S84

[15] Peng, Q.Y., Wang, X.T., Zhang, L.N. and Chinese Critical Care Ultrasound Study Group (CCUSG) (2020) Findings of Lung Ultrasonography of Novel Corona Virus Pneumonia during the 2019-2020 Epidemic. Intensive Care Medicine, 46, 849-850. https://doi.org/10.1007/s00134-020-05996-6

[16] Wang, Y., Dong, C., Hu, Y., et al. (2020) Temporal Changes of CT Findings in 90 Patients with COVID-19 Pneumonia: A Longitudinal Study. Radiology, 296, E55-E64. https://doi.org/10.1148/radiol.2020200843

[17] Jamil, S., Mark, N., Carlos, G., Cruz, C.S.D., Gross, J.E. and Pasnick, S. (2020) Diagnosis and Management of COVID-19 Disease. American Journal of Respiratory and Critical Care Medicine, 201, P19-P20. https://doi.org/10.1164/rccm.2020C1

[18] Levine, R. and Caputo, N. (2020) CT Scan of a COVID-Positive Patient. JACEP Open, 1, 143-147. https://doi.org/10.1002/emp2.12073

[19] Recovery. Randomized Evaluation of COVID-19 Therapy. ClinicalTrials.gov Identifier: NCT04381936.

[20] Wuhan CT Scans Reliable for COVID-19 Diagnosis, Limited for Differentiation. Appl Radiol. By News Release, 9 March 2020.

[21] ACR Issues Statement for Use of Chest Radiography, CT for Suspected COVID-19 Infection. Appl Radiol. 11 March 2020.

[22] Czawlytko, C., Hossain, R. and White, C.S. (2020) COVID-19 Diagnostic Imaging Recommendations. Applied Radiology, 49, 10-15.

[23] Ilyas, N., Azuine, R. and Tamiz, A. (2020) COVID-19 Pandemic in Pakistan. International Journal of Translational Medical Research and Public Health, 4, 37-49. https://doi.org/10.21106/ijtmrph.139

[24] Goldmen, G.D., Lye, C.B.D., Hui, D.S., Marks, K.S., Bruno, R., Montejano, R., 
Spinner, C.D., et al. (2020) Remdesivir for 5 or 10 Days in Patients with Severe Covid-19. The New England Journal of Medicine, 383, 1827-1837.

https://doi.org/10.1056/NEJMoa2015301 